Moyle W. (2019). The promise of technology in the future of dementia care. Nature Reviews Neurology 15, 353-359.

\title{
SCIENCE AND SOCIETY
}

The promise of technology in the future of dementia care

Wendy Moyle

\begin{abstract}
Dementia is a leading cause of disability, and the prevalence of dementia is steadily increasing. Although people with dementia are living longer lives in the community, without adequate support for their declining physical and psychological needs, the majority of these individuals end up in nursing homes. With no cure in sight, and in the context of population ageing, we must consider how to care for these individuals in the future. Technologies that augment existing care can maintain a person comfortably in their community, maximize individual autonomy and promote social participation. However, to date, such technologies have rarely been used in dementia care. This Perspectives article highlights the need for affordable and appropriate technologies to assist future dementia care, outlines some of the technologies currently available, and describes the many challenges to integration of such technologies. Finally, guidelines are suggested for the development and implementation of new technologies in dementia care.
\end{abstract}

\section{[H1] Introduction}

Approximately every $3 \mathrm{~s}$ a person somewhere in the world is diagnosed with a chronic progressive neurological syndrome associated with dementia ${ }^{1}$. Alzheimer disease (AD) is the most common cause of dementia. Currently, around 50 million people are living with dementia worldwide ${ }^{2}$. The number of people with dementia is doubling every 20 years, in part owing to ageing of the population, and by 2050 is predicted to reach an estimated 152 million people ${ }^{1}$. (Figure 1) Much of this growth in dementia will continue to be in developing countries and, in particular, countries with a rapid increase in the ageing population, such as China and India ${ }^{1}$. These statistics are fairly new in the span of human history: even as recently as the 1900s, individuals in Western countries rarely 
lived into their 90s, whereas today the largest growth in the population is in individuals aged 80 years or over ${ }^{3}$. As a result, age-related conditions such as AD are increasing in prevalence. The initial symptoms of AD are losses in short-term memory, which are followed by declines in long-term memory, language, problem solving, and other cognitive functions. Affected individuals initially require assistance with tasks related to memory and navigation; as the syndrome progresses, they require increasing levels of support for all activities of daily living.

In the past, people with dementia were often banished to so-called lunatic asylums ${ }^{4}$. However, once it was understood that people with dementia had a medical condition that was destroying their brains, they were accepted into nursing homes where they often would arrive early in the trajectory of their condition and live many years locked away from society. Today, increased understanding of the importance of personhood has helped people with dementia to remain as long as possible in their own community where family and friends, alongside community support services, manage the person's daily needs. Despite these improvements in care, however, people with dementia often continue to feel stigmatized by a society that often does not understand what it is to have a diagnosis of dementia, or what such a condition means to the person, their family, and friends ${ }^{5,6}$. Being treated as an 'outsider' or person of little importance encourages a sense of being an outcast of society. Perhaps because dementia has no cure, this sense of fear and hopelessness continues to influence the care offered to people with dementia in Western countries. In other countries, by contrast, dementia is accepted as a normal condition of ageing and affected people are encouraged to engage and remain in their community ${ }^{7}$. Such cultural variations contribute to large geographical discrepancies in dementia treatment and care.

It is important to consider what types of care should be offered to people with dementia in the future. Other key questions are who will care for this population and what will that care look like? Will dementia continue to be seen as a hopeless diagnosis, or will it be viewed more positively as a condition in which people know they have a future as part of a society that understands their needs and can care for those needs? Will people with dementia continue to be placed in nursing homes once the required level of community care cannot be provided? Or will they only enter end of life or palliative care settings to live out their final weeks or days? In the context of an ageing population we must also wonder whether there will be enough younger, healthy people 
to provide this care. In super-aged countries, such as Japan, there are already not enough young people to provide care for their ageing population. Japan has responded to this lack of young workers by pushing forward with the development of technologies to assist with care provision.

A US national consensus panel convened by the Johns Hopkins Translational Aging Services Core recommends home-based care for people with dementia as the nexus of economically efficient long-term care models, and the preference is for people with dementia to stay in their own home as long as possible ${ }^{8}$. Accordingly, in this Perspectives article I discuss several areas highlighted by the Johns Hopkins panel in which technology can support home-based care for people living with dementia8: assessment and monitoring technologies; assistive devices; therapeutic devices; and caregiver-supportive technologies. Unfortunately, the effectiveness of these technologies is complicated by the stage and speed of development. Some technologies are in the ascent phase, where research costs have been recovered and the technology is entering evidence-based practice, whereas other products are early in development. Not all products are fit for purpose and few are affordable or widely available. Here, I discuss the challenges facing integration of technologies into dementia care and suggest guidelines for their development and implementation. It is imperative that we build a future alongside smart assistive technology and robotics to augment human care provision and thereby transform dementia services and support. There is little doubt that the future will hold a stronger place for these technologies.

\section{[H1] The technologies}

Current technologies have focused on helping people who are in the early stages of their syndrome to remain independent, improve social participation, security and monitoring of physical and behavioural status (Table 1). These technologies could help to fill a gap in care support if they can help to maintain a person comfortably in their community and promote independence, positive mood, and quality of life for the person living with dementia, as well as supporting the family carer. However, future dementia care demands technology that can also reduce stigmatization and discrimination towards people with dementia. To date, no technologies have been developed that achieve this.

\section{[H2] Assessment and monitoring}


The past few years have seen a huge increase in the demand for smart home technology, such as Apple's Google Home, that reminds us of the date and tells us what the weather will be like tomorrow, as well as takes control of our home lighting, heating, and oven from a smart phone. Such technologies are non-intrusive in that they do not require ongoing assistance from human interaction, are useful for society at large and they can also help people with dementia, especially those early in their disease course, to remain independent.

Older people with dementia living alone in the community face risks to their safety, health, and psychological wellbeing. Advances in artificial intelligence (AI) including the Internet of Things (IoT) can help individuals to remain independent. Wearable devices connected via the IoT enable carers and health professionals to monitor an individual's environment, health and wellbeing in real time. Such systems learn the physical habits and symptoms of the person and can raise concern before the occurrence of adverse events, such as a fall or severe illness. However, effective predictive models require a personalized approach to monitoring and, therefore, can be an expensive option.

Older people with dementia living alone often face loneliness and social isolation ${ }^{9}$. Installation of sensors in the home can provide an effective means of monitoring wellbeing, physical activity and social participation. For example, sensors can detect behaviours, such as time spent in particular rooms in the house, time spent lying prone, daytime and night-time sleep, and time spent out of the home. These sensors can alert carers or emergency services if they detect any potential problems. Such information can help to detect individuals who are at risk of social isolation or of wandering ${ }^{10}$, so that appropriate care programmes can be put into place that enable people with dementia to stay in the community for longer.

\section{[H2] Assistive robotic technologies}

Assistive technology can help people remain independent and provide relatives with reassurance. Over the past decade, researchers have reported that professional caregivers and older people are curious about and open to the use of robots in care ${ }^{11,12}$. Assistive robots can provide physical care and social support. They can also provide reminders about appointments, medications, and dietary requirements, and alert individuals to the risk of a fall or dehydration. Importantly, they do not arrive with any 
'social baggage', which can impede care, and they do not judge people.

One such robot is RAMCIP (Robotic assistant for mild cognitive impairment (MCI) patients at home), a service robot developed through a recently completed EU 2020 Horizon Project ${ }^{13}$. The eight research partners from six countries used a collaborative design process to identify the requirements for a robot intended to assist older people with MCI to stay in their own homes. This process incorporated focus groups and surveys of medical staff $(n=100)$, caregivers $(n=81)$ and potential end users $(n=83)^{14}$. RAMCIP performs tasks such as detecting falls, turning on lights, monitoring individuals, bringing medications and water, picking up objects and connecting the person to their family via a video conferencing system. To date RAMCIP has been pilot trialled in the home of 10 users $^{15}$.

Another example is Care-O-Bot, a mobile assistant developed at the Fraunhofer Institute for Manufacturing Engineering and Automation, Germany. Care-O-Bot was built to support people in various activities of daily living. Development of the robot commenced in 1998 and, in 2015, version 4 was released ${ }^{16}$. Unlike most current robots, Care-0-Bot can fulfill a range of roles owing to a modular control system that can be configured for specific customer situations. The roles of Care-O-Bot include sales assistant, museum guide, and personal care assistant; in the latter mode, Care-O-Bot performs tasks such as fetching and carrying, ensuring adequate hydration, and reminders ${ }^{16}$. Importantly, Care-0-Bot uses AI to evaluate the mood of the patient and considers this in its individual communication responses ${ }^{17}$.

Voice-activated service robots have been developed that can undertake single tasks, such as physical guidance and assistance, and lifting individuals ${ }^{18}$. Furthermore, robotic wheelchairs that can move an individual while avoiding obstacles have been developed in Japan ${ }^{19}$. However, given that people are likely to remain in the community as long as possible in the future and will enter nursing homes only for palliative or end of life care, robots need to be sufficiently advanced to undertake multiple tasks within the home environment, to avoid the need for purchase and use of multiple technologies ${ }^{20}$.

One of the greatest challenges faced by people after receiving a diagnosis of dementia is the loss of independence associated with cancellation of their driver's license owing to cognitive impairment. The future holds opportunities to maintain these individuals' independence through the introduction of self-driving cars. Although 
considerable scepticism persists about the safety of such cars, the evidence is going some way towards alleviating those fears ${ }^{21,22}$. A future exists in which people with dementia will be able to call for an autonomous car to take them to their clinic appointments, supermarket, family, and friends, all without fear of getting lost or causing an accident.

However, although a number of apparently promising assistive and robotic technologies are being developed, such products often do not reach the market for which they are intended, and only a limited number become commercially available. ${ }^{23}$ Reasons for this situation might be related to their development in universities or research institutes, which do not necessarily seek opportunities for commercialization of their products, and to the feasibility of the technology to accomplish the tasks assigned. In some cases, developers have paid only limited attention to the needs of end users from conceptualization of the product through to testing and commercialization ${ }^{24}$. Finally, the lengthy time necessary for development of sophisticated robots generates high production costs and competitive technologies may be produced before products are commercialised 25,26 .

\section{[H2] Therapeutic technologies}

Several different versions of therapeutic robots have been designed to support individuals with dementia. Telepresence robots, for example, are remotely controlled mobile video-conference systems that can improve social participation through videoconferencing with family and friends anywhere in the world. Other robotic systems can provide stimulating entertainment, and virtual reality can stimulate new experiences and reduce apathy ${ }^{27,28}$. Other robots include cute and cuddly therapeutic pet-type robots, such as Paro, which was developed in Japan and modelled on a baby harp seal ${ }^{29}$. Such robots encourage engagement and social connection without the support needs of a real animal. Varying levels of evidence support the utility of each of these devices, with Paro having the best evidence available for reducing the behavioural and psychological symptoms of dementia ${ }^{29-31}$.

\section{[H2] Caregiver support}

An increasing number of applications are being developed to assist and support caregivers. Applications used with smart photo albums or tablets can be used for 
reminiscence therapy ${ }^{32}$. These are currently some of the most useful supportive devices.

In addition, lifting robots such as RIBA II can enable patients up to $80 \mathrm{~kg}$ in weight to be safely transferred from the floor or bed into a chair or wheelchair ${ }^{33}$. Assistive devices, such as the Obi robotic spoon ${ }^{34}$, enable people with limited mobility to feed themselves without spilling food. These technologies help individuals to remain independent and also reduce the burden on carers.

\section{[H1] Obstacles and challenges}

Despite the surge in technological development over the past decade, societal views about the acceptability of robots can be a barrier to their use. Acceptance might be dependent on whether robots are seen as technology that works alongside or as a supplement to carers, or as a replacement for human employees ${ }^{35-37}$. Although some members of society might imagine a future where care workers will all be robots ${ }^{38}$ such a future will not occur as long as humans value the importance of human life and caregiving. Care for people with dementia is complex and demands a flexible approach suited to the person's physical and cognitive needs. It would take an incredibly sophisticated AI system to predict and respond to all their personal care needs appropriately. I imagine a future situation where robots will help with particular tasks, and offer a substitute for human care during those inevitable times when human assistance is not available.

Robots potentially have many advantages compared with human care. They can be programmed to provide care in an emotionally supportive way that avoids abuse of the rights of the person. Human care can be less consistent and the quality of humanprovided care depends on how busy the carer is and how they feel about the individual. Such factors, in the worst-case scenario, can result in the abuse of patients by their carers. However, ethical arguments continue to be made against the use of technology in care and in particular against the use of robots. For example, some individuals have argued that robots should not provide care unless they can give the impression of emotional engagement with care recipients ${ }^{39}$. Despite advances in this area, the majority of available technologies do not appropriately recognize or react to human emotions ${ }^{40}$.

Debate is ongoing worldwide as to whether robots will be good or bad for society. In 2015, a survey of public attitudes towards robots found that, overall, EU 
citizens presented positive attitudes about robots and were willing to have robots assist them in their work ${ }^{41}$. Interestingly, these survey respondents showed widespread agreement (60\%) that robots should not care for children, older people, or disabled persons. However, governmental policy groups are moving forward with different recommendations suggesting these groups have not been speaking to each other. For example, the European Commission ICT-AGE research project, which aimed to develop guidelines for member states on how to design long-term care strategies to help older people to live independently, recommended in their 2015 report that assistive robots and social robots should be included in technology-enabled services as a means to help older people live at home independently ${ }^{42}$. Furthermore, the European Commission continues to support opportunities to develop AI systems and robots to improve the care of older people ${ }^{43}$.

In spite of these advances, ethical issues remain prominent in the literature, with the argument being that these technologies might deceive patients and take away the dignity of care ${ }^{44-46}$. For example, a person with dementia might perceive a robotic animal to be a 'real' animal. These dilemmas remain to be addressed and, in addition to the high cost of the products, might also contribute to the slow adoption of robotic and assistive technologies in dementia care ${ }^{40}$. However, with changing attitudes to technology and ongoing technical development, the ethical issue in the future might become 'why can't I have such technologies?', rather than 'should we introduce these technologies?'.

Humanoid robots might find increased acceptance, as these robots look humanlike and interact naturally with people. However, concerns arise, such as who is responsible for repairs if the robot breaks down? This may be a problem if a worldwide service contract arrangement has not been organised. And what do we do if the person becomes emotionally attached to their robot and it is unrepairable? Would the individual willingly transfer that attachment to a newer version of the technology, in the same way as they accepted the old technology. A famous example of technology attachment is Stephen Hawkin's attachment to his voice. In 1988, he was presented with a new speech synthesizer. However, the voice was different to the original voice he had grown accustomed to and he asked Speech Plus to replace it with the original 1980 version ${ }^{47}$. In Japan, owners are often so attached to their robotic dogs that unrepairable ones are given funerals as a way of saying goodbye $\mathrm{e}^{48}$. 
Importantly, the legal implications of technologies that collect, store and upload health data have not been widely considered. Unless privacy and security are addressed, these devices place users at risk of their information being widely disseminated. Furthermore, a growing number of countries require technologies to be approved for specific medical indications by regulatory bodies such as the US Food and Drug Administration (FDA, https://www.registrarcorp.com/fda-medical-devices/); the Australian Therapeutic Goods Administration (https://www.tga.gov.au/regulationsoftware-medical-device); and the European Commission (https://ec.europa.eu/growth/sectors/medical-devices/regulatory-framework_en). These bodies aim to assure the safety and effectiveness of technologies used as medical devices or involving the diagnosis, prevention, monitoring, treatment or alleviation of disease. However, the process of approval is so complex that some medical device developers believe it impedes innovation and delays the availability of new technology, and they advocate that this approval process needs to be simplified ${ }^{49,50}$. The robots discussed in this Perspectives article are considered to be medical devices because they are intended to be used in the treatment of dementia, such as for reducing its behavioural and psychological symptoms or assisting with functional disability or communication. However only Paro has gone through the complex process of gaining regulatory approval.

To date, although these technologies are used in several countries, they are not used globally in dementia care. A key issue is related to the limited end user engagement in their design and development; as a result, the technologies are frequently seen as being unfit for purpose by carers, patients and health-care providers ${ }^{51}$. Furthermore, most potential users remain ignorant of the availability of these technologies. The high cost of some devices places them beyond the reach of most members of society, although Paro achieved medical device status in the USA in 2009, which enables clients to be reimbursed through Medicare and some private insurance companies for prescribed treatments of therapy with Paro ${ }^{52}$. Furthermore, in Australia elderly patients have been able to purchase Paro through the government-funded Home Care Packages programme ${ }^{53}$. Such schemes have enabled patients to access assistive technologies regardless of their financial circumstances.

Finally, carers require training in how and when to use the technology, how to obtain technological support and how to monitor and assess its use. Home 
environments might also need to be adapted to facilitate the use of technologies (in particular, storage of large robotic platforms).

\section{[H1] Guidelines}

Box 1 outlines key criteria that should guide technological development, which are based on empirical evidence and expert opinion. The development of technologies that will be useful for end users requires their engagement at all levels of design and implementation, not just a short trial once the device has been created. Such involvement ensures that end users' needs and concerns are adequately addressed.

Notably, governments need to show that they value innovation and support sophisticated but high-risk initiatives that have the potential to improve future dementia care. Universities need to move beyond research and aim for the commercialization of products that have been shown to be useful. Once products become commercially available, their cost will reduce as greater numbers of people purchase the products. Importantly, new technologies must be able to undertake a multitude of tasks, particularly those related to self-care, and must deliver those tasks according to the user's preferences ${ }^{23,54}$. Robots must also be able to react in an acceptable manner to human emotions. Finally, societal views on monitoring and privacy must be carefully considered to obtain the full benefit of these devices in the care of older people with cognitive impairment.

\section{[H1] Conclusions}

This Perspectives article addresses the contribution of technologies to the future of dementia care. As the number of people with dementia is expected to continue to grow well into the future, it is likely that we will reach a stage where we have little choice but to integrate technology alongside human-provided care in order to manage the needs of people living with dementia. Although ethical challenges continue to raise concerns, we must learn to think of technology as part of our society if we are to broaden the opportunities for home-based care of people with dementia. The main focus of the groups producing these technologies should be on involving both people with dementia and their carers in the design of ethical products that meet end-user needs. Such technologies offer great promise for assisting with the physical and cognitive challenges 
of people with dementia, as well as in helping to reduce the burden on carers and the challenges of an ageing workforce.

\section{Wendy Moyle}

Griffith University, Menzies Health Institute Queensland, Nathan, Brisbane, QLD 4111, Australia.

e-mail: w.moyle@griffith.edu.au

\section{References}

1 Alzheimer's Disease International. World Alzheimer Report 2018: The State of the Art of Dementia Research: New Frontiers. (ADI, London, 2018).

2 World Health Organization. Towards a Dementia Plan: A WHO Guide. (World Health Organization, Geneva, 2018).

3 United Nations. World Population Prospects: The 2017 Revision. (Department of Economic and Social Affairs, Geneva, 2017).

4 Andrews, E. S. Institutionalising senile dementia in 19th-century Britain. Sociol Health Illn 39, 244-257 (2017).

5 Gove, D., Small, N., Downs, M. \& Vernooij-Dassen, M. General practitioners' perceptions of the stigma of dementia and the role of reciprocity. Dementia (London) 16, 948-964 (2017).

6 Weisman De Mamani, A., Weintraub, M. J., Maura, J., Martinez de Andino, A. \& Brown, C. A. Stigma, expressed emotion, and quality of life in caregivers of individuals with dementia. Fam Process 57, 694-706 (2018).

7 Kristanti, M. S., Engels, Y., Effendy, C., Utarini, A. \& Vernooij-Dassen, M. Comparison of the lived experiences of family caregivers of patients with dementia and of patients with cancer in Indonesia. Int Psychogeriatr 30, 903-914 (2017).

8 Samus, Q. M. et al. Home is where the future is: the BrightFocus Foundation consensus panel on dementia care. Alzheimers Dement 14, 104-114 (2018).

9 Poey, J. L., Burr, J. A. \& Roberts, J. S. Social connectedness, perceived isolation, and dementia: does the social environment moderate the relationship between genetic risk and cognitive well-being? Gerontologist 57, 1031-1040 (2017). 
10 Goonawardene, N., Toh, X. P. \& Tan, H.-P. in Human aspects of IT for the aged population. Applications, services and contexts Vol. 2 (eds. Zhaou, J \& Salvendy, G.) 378-392 (Springer, 2017).

11 Beer, J. M. et al. Older users' acceptance of an assistive robot: attitudinal changes following brief exposure. Gerontechnology 16, 21-36 (2017).

12 Vandemeulebroucke, T., de Casterle, B. D. \& Gastmans, C. How do older adults experience and perceive socially assistive robots in aged care: a systematic review of qualitative evidence. Aging Ment Health 22, 149-167 (2018).

13 The RAMCIP Consortium. What is RAMCIP? Robotic Assistant for MCI Patients at home [online] (17 March 2019) https://ramcip-project.eu (2018)].

14 Gerlowska, J. et al. Assessment of perceived attractiveness, usability, and societal impact of a multimodal robotic assistant for aging patients with memory impairments. Front Neurol 9, 392 (2018).

15 The RAMCIP Consortium. RAMCIP at the 2018 International conference on Intelligent Robots and Systems (IROS 2018). Robotic Assistant for MCI Patients at home [online] (17 March 2019] https://ramcip-project.eu/content/ramcip-2018international-conference-intelligent-robots-and-systems-iros-2018 (2018)].

16 Fraunhofer Institute for Manufacturing Engineering and Automation. Care-O-bot 4. Fraunhofer Institute for Manufacturing Engineering and Automation [online] (17 March 2019) https://www.care-o-bot.de/en/care-o-bot-4 (2019)].

17 Fraunhofer Institute for Manufacturing Engineering and Automation. Fraunhofer start-up award 2017 for Mojin Robotics GmbH. Fraunhofer Institute for Manufacturing Engineering and Automation [online] (17 March 2019) https://www.fraunhofer.de/en/press/researchnews/2018/February/fraunhofer_startup_award_2017_for_mojin_Robotics.html (2017)].

18 Feuilherade, P. Robots pick up the challenge of home care needs. International Electrotechnical Commission [online] (17 March 2019) https://iecetech.org/Technology-Focus/2017-02/Robots-pick-up-the-challenge-ofhome-care-needs (2017)].

19 Shiomi, M., Lio, T., Kamei, K., Sharma, C. \& Hagita, N. Effectiveness of social behaviors for autonomous wheelchair robot to support elderly people in Japan. PLoS One 10, e0128031 (2015). 
20 Bedaf, S., Gelderblom, G. J. \& de Witte, L. Overview and categorization of robots supporting independent living of elderly people: what activities do they support and how far have they developed. Assist Technol 27, 88-100 (2015).

21 Pettigrew, S., Talati, Z. \& Norman, R. The health benefits of autonomous vehicles: public awareness and receptivity in Australia. Aust N Z J Public Health 42, 480-483 (2018).

22 Wong S. Driverless cars take on Oxford. New Sci 238, 16-16 (2018).

23 Bedaf, S., Marti, P., Amirabollahian, F. \& de Witte, L. A multi-perspective evaluation of a service robot for seniors: the voice of different stakeholders. Disabil Rehabil Assist Technol 13, 592-599 (2018).

24 Mordoch, E., Osterreicher, A., Guse, L., Roger, L. \& Thompson, G. Use of social commitment robots in the care of elderly people with dementia: a literature review. Mauritas 74, 14-20 (2013).

25 Cleetus K. J. in Concurrent engineering: tools and technologies for mechanical system design (ed Haug, E.J.) 41-74 (Springer-Verlag Berlin Heidelberg, 1993).

26 Rafinejad D. in Core competency, core activies, and leveraging resources (ed Rafinejad, D.) 270-273 (J. Ross Publishing, 2007).

27 Foloppe, D. A., Richard, P., Yamaguchi, R., Etcharry-Bouyx, F. \& Allain, P. The potential of virtual reality-based training to enhance the functional autonomy of Alzhiemer's disease patients in cooking activities: a single case study. Neuropsychol Rehabil 28, 709-733 (2018).

28 Lizuka, A. et al. Pilot randomized controlled trial of the GO game intervention on cognitive function. Am J Alzheimers Dis Other Demen 33, 192-198 (2018).

29 Moyle, W. et al. Use of a robotic seal as a therapeutic tool to improve dementia symptoms: a cluster-randomised controlled trial. J Am Med Dir Assoc 18, 766-773 (2017).

30 Jones, C. et al. Does cognitive impairment an agitation in dementia influence intervention effectiveness? findings from a cluster-randomised controlled trial with the therapeutic robotic, PARO. J Am Med Dir Assoc 19, 623-626 (2018).

31 Joranson, N. et al. Group activity with PARO in nursing homes: systematic investigation of behaviors in participants. Int Psychogertiatr 28, 1345-1354 (2016).

$32 \mathrm{Hu}$, H.-J., Wu, P.-F. \& Wang-Chin, T. in Human aspects of IT for the aged population. Applications, aervices and contexts (eds Zhaou, J. \& Salvendy, G.) 42-52 (Springer, 2017). 
33 RIKEN-TRI Collaboration Center for Human-Interactive Robot Research (RTC) \& RIKEN (The Institute of Physical and Chemical Research). World's first robot that can lift up a human in its arms. RIBA, Robot for Interactive Body Assistance [online] (17 March 2019) http://rtc.nagoya.riken.jp/RIBA/index-e.html (2018)].

34 Desin LLC. Robotic feeding device designed for home care. Obi Robot [online] (17 March 2019) https://meetobi.com (2018)].

35 de Graaf, M.M.A,, Allouch, S.B. \& Klamer, T. Sharing a life with Harvey: exploring the acceptance of and relationship-building with a social robot. Comput Human Behav 43, 1-14 (2015).

36 Lee, H.R, Tan, H. \& Sabanovic, S. in IEEE International Symposium on Robot and Human Interactive Communication (RO-MAN) 312-317 (Columbia University, NY., USA, 2016).

37 Pfadenhauer, M. \& Dukat, C. Robot caregiver or robot-supported caregiving? the performative development of the social robot PARO in dementia care. Int J Soc Robot 7, 393-406 (2015).

38 Trynacity K. Close enough to care: replacing human caregivers with robots in homecare. Master of Arts in Intercultural and International Communication thesis, Royal Roads University, (2015).

39 Wachsmuth, I. Robots like me: challenges and ethical issues in aged care. Front Psychol 9, 432 (2018).

40 Robillard, J. M., Cleland, I., Hoey, J. \& Nugent, C. Ethical adoption: a new imperative in the development of technology for dementia. Alzheimers Dement 14, 1104-1113 (2018).

41 European Commission. Autonomous systems report. (TNS Opinion \& Social, 2015).

42 Carretero, S. Technology-enabled services for older people living at home independently: lessons for public long-term care authorities in the EU Member States'. (Seville, Joint Research Centre, Institute for Prospective Technological Studies, JRC Scientific and Technical Reports Series, 2015).

43 CORDIS. The world's first culturally sensitive robots for elderly care. CORDIS [online] (17 March 2019) https://cordis.europa.eu/news/rcn/130441/en; https://cordis.europa.eu/news/rcn/129383/en (2018)].

44 Coeckelbergh, M. Artificial agents, good care, and modernity. Theor Med Bioeth 36, 265-277 (2015). 
45 Matthias, A. Robot lies in health care: when is deception morally permissible? Kennedy Inst Ethics J 25, 169-192 (2015).

46 Metzler, T. A. \& Barnes, S. J. Three dialogues concerning robots in elder care. Nurs Philos 15, 4-13 (2014).

47 Holly, R. Stephen Hawking gets a tech upgrade from Intel, but keeps his original voice. Geek.com [online] (17 March 2019) https://www.geek.com/geekcetera/stephen-hawking-gets-a-tech-upgrade-from-intel-but-keeps-his-originalvoice-1610726 (2014)].

48 Burch, J. In Japan, a Buddhist Funeral Service for Robot Dogs. National Geographic [online] (17 March 2019) https://www.nationalgeographic.com/travel/destinations/asia/japan/in-japan--abuddhist-funeral-service-for-robot-dogs (2018)].

49 Santos Rutschman, A. Faster approval for drugs and medical devices under the 21st Century Cures Act raises concerns for patient safety. The Conversation [online] (17 March 2019) https://theconversation.com/faster-approval-for-drugs-andmedical-devices-under-the-21st-century-cures-act-raises-concerns-for-patientsafety-70383 (2017)].

50 Van Norman, G. A. Drugs, devices and the FDA: Part 2. An overview of approval processes: FDA approval of medical devices. JACC Basic Transl Sci 1, 277-287 (2016).

51 Shaw, J., Shaw, S., Wherton, J., Hughes, G. \& Greenhalgh, T. Studying scale-up and spread as social practice: theoretical introduction an empirical case study. $J$ Med Internet Res 19, e244 (2017).

52 Alzforum. Technology for Patients: Purring Robots, Digital Data-Gathering. Alzforum [online] (17 March 2019) https://www.alzforum.org/news/conferencecoverage/technology-patients-purring-robots-digital-data-gathering (2018)].

53 Australian Government Department of Health. About the Home Care Packages Program, Australian Government Department of Health [online] (17 March 2019) https://agedcare.health.gov.au/programs/home-care/about-the-home-care-packagesprogram (2017)].

54 Schwenk, M. et al. Sensor-derived physical activity parameters can predict future falls in people with dementia. Gerontology 61, 483-492 (2014). 
55 Neubauer, N. A. et al. What do we know about technologies for dementia-related wandering? a scoping review. Can J Occup Ther 85, 196-208 (2018).

56 Gaugler, J. E. et al. Six-month effectiveness of remote activity monitoring for persons living with dementia and their family caregivers: an experimental mixed methods study. Gerontologist 59, 78-89 (2019).

57 Bemelmans, R., Gelderblom, G., Jonker, P. \& de Witte, L. Assistive socially assistive robots in elderly care: a systematic review into effects and effectiveness. $J$ Am Med Dir Assoc 13, 114-120 (2012).

58 Kouroupetroglou, C. et al. Interacting with dementia: the MARIO approach. Stud Health Technol Inform 242, 38-47 (2017).

59 Whelan, S. et al. Investigating the effect of social robot embodiment. Stud Health Technol Inform 242, 523-526 (2017).

60 Moyle, W. et al. Connecting the person with dementia and family: a feasiblity study of a telepresence robot. BMC Geriatr 14, 7 (2014).

61 Liang, A. et al. A pilot randomized trial of a companion robot for people with dementia living the the community. J Am Med Dir Assoc 18, 871-878 (2017).

62 Brown, E. et al. Technologies for dementia care: opportunities, challenges, and current practices. J Appl Gerontolol 38, 73-91 (2019).

63 Hill, N. T. et al. Computerized cognitive training in older adults with mild cognitive impairment or dementia: a systematic review and meta-analysis. Am J Psych 174, 329-340 (2016).

64 Lee, G. J. et al. A comparison of the effects between 2 computerized cognitive training programs, Bettercog and COMCOG, on elderly patients with MCI and mild dementia: a single-blind randomized controlled study. Medicine 97, e13007 (2018).

65 Stillwell, S. B., Fineout-Overholt, E., Melnyk, B. M. \& Williamson, K. M. Evidencebased practice, step by step: searching for the evidence. Am J Nurs 110, 41-47 (2010). 


\section{Acknowledgements}

Thank you to Jenny Murfield and Lee Earle for their help with referencing and editing of this article.

\section{Competing interests}

The author declares no competing interests.

\section{Publisher's note}

Springer Nature remains neutral with regard to jurisdictional claims in published maps and institutional affiliations.

\section{Further information}

Alzheimer Master

www.alzheimermaster.com

Care-O-Bot

https://www.care-o-bot.de/en/care-o-bot-4.html

COMCOG Training Tool

https://home.neofect.com/blog/an_attention_and_memory_training_tool

CommunicATe Photo Album

www.communicateat.com.au

Dawn Clocks

info@dawn-clocks.com

European Commission Medical Devices Regulatory Framework

(https://ec.europa.eu/growth/sectors/medical-devices/regulatory-framework_en)

Giraff Telepresence

https://www.camanio.com/en/products/giraff/ 
Google Home

https://store.google.com/au/product/google_home

Just Checking wireless movement sensors

www.justchecking.com.au

Luminosity Brain Training

www.luminosity.com

Mario Robot

http://www.mario-project.eu/portal/

MiRo

http://consequentialrobotics.com/miro/

Obi Robotic Spoon

https://meetobi.com/

Paro

http://www.parorobots.com/

RAMCIP (Robotic Assistant for MCI patients)

http://www.ramcip-project.eu

Riken (Robear)

http://www.riken.jp/en/pr/press/2015/20150223_2/

Therapeutic Goods Administration of Australia (https://www.tga.gov.au/regulationsoftware-medical-device) 
Tunstall Watch

http://www.tunstallhealthcare.com.au/find-me-tunstall-watch

US Food and Drug Administration (FDA) (https://www.registrarcorp.com/fda-medicaldevices/)

Figure 1: International dementia statistics over time and projected.

Legend Past dementia statistics from 2001 -20018 and future predictions of dementia statistics from $2030-2050$ 


\section{Box 1: Guidelines for the development of technologies for dementia care Required criteria}

Technology is based on a theoretical framework that shapes the technological innovation

Development team includes experts in dementia as well as end users such as carers, patients, developers, and healthcare professionals

Conceptualized and developed with input from end users at all stages

Trialled and tested by end users and adapted to their needs

Technology must be capable of multiple tasks to enable sustainability across the stages of dementia

Technology must be well-tested and beyond the early prototype stage for commercialization to be considered

Technology must adhere to privacy standards for the collection, use, storage and transmission of patient data

Pricing of the technology must consider not only R\&D and production but also a viable purchase cost for the intended market

Robots must be developed that react appropriately to human emotions

Technologies must be easily incorporated into the Internet of Things

Technological support must be developed and delivered using multiple platforms (such as telephone helplines, online videos and printed problem-solving information)

- Research exploring the effectiveness of the technology must move from small descriptive studies to incorporate larger randomized controlled trials

- Research must include cost-effectiveness of technology

\section{Criteria supporting technology development}

- Governments must value innovation and support technology development

- Universities and research institutes must promote the commercialization of products they have developed

- Medical device regulation bodies must aid developers to gain approval for devices

- Potential adverse effects of the technology must be reported

- National and international organizations focusing on Alzheimer disease and other causes of dementia should provide detailed information* on available technologies

*Including, for example, case studies, examples of use, cost and where they can be purchased. 
Table 1: Technologies that can support people with dementia and carers

\begin{tabular}{|c|c|c|c|c|}
\hline $\begin{array}{l}\text { Device name } \\
\text { (manufacturer) }\end{array}$ & Functions & Developed for & $\begin{array}{l}\text { Level of } \\
\text { evidence* }\end{array}$ & Refs \\
\hline \multicolumn{5}{|l|}{ Monitoring } \\
\hline $\begin{array}{l}\text { Google Home } \\
\text { (Apple) }\end{array}$ & $\begin{array}{l}\text { Calendar reminders, weather, controls } \\
\text { lighting, heating through smart phone }\end{array}$ & General use & Level VII & NR \\
\hline $\begin{array}{l}\text { Find Me Tunstall } \\
\text { Watch } \\
\text { (Tunstall) }\end{array}$ & $\begin{array}{l}\text { GPS monitoring. Can aid orientation, } \\
\text { location tracking, fall detection and } 24 / 7 \\
\text { support }\end{array}$ & $\begin{array}{l}\text { Cognitively } \\
\text { impaired }\end{array}$ & Level V & 54,55 \\
\hline $\begin{array}{l}\text { Wireless movement } \\
\text { sensors } \\
\text { (Just Checking) }\end{array}$ & $\begin{array}{l}\text { Text and email messages to alert carer. } \\
\text { Information on activity and when } \\
\text { different rooms are used }\end{array}$ & $\begin{array}{l}\text { Cognitively } \\
\text { impaired }\end{array}$ & Level II & 56 \\
\hline \multicolumn{5}{|l|}{ Assistive robotics } \\
\hline $\begin{array}{l}\text { Care-0-Bot } \\
\text { (Fraunhofer } \\
\text { Institute for } \\
\text { Manufacturing } \\
\text { Engineering and } \\
\text { Automation) }\end{array}$ & $\begin{array}{l}\text { Select from a range of applications: fetch } \\
\text { and carry; monitor; reminders; } \\
\text { communication }\end{array}$ & $\begin{array}{l}\text { Older people \& } \\
\text { cognitively } \\
\text { impaired }\end{array}$ & Level V & $\underline{57}$ \\
\hline $\begin{array}{l}\text { RAMCIP } \\
\text { (EU Horizon } 2020 \\
\text { project) }\end{array}$ & $\begin{array}{l}\text { Reminds individuals about daily tasks } \\
\text { such as taking medications, to bring fluid } \\
\text { and food, can detect falls, communication } \\
\text { via video conference }\end{array}$ & MCI & Level VI & $\underline{13,14}$ \\
\hline $\begin{array}{l}\text { Riken and Robear } \\
\text { (RIKEN-SRK) }\end{array}$ & $\begin{array}{l}\text { Can transfer frail people from floor to } \\
\text { chair or bed }\end{array}$ & $\begin{array}{l}\text { Older people \& } \\
\text { disabled }\end{array}$ & Level VII & NR \\
\hline \multicolumn{5}{|l|}{$\begin{array}{l}\text { Assistive } \\
\text { Innovations }\end{array}$} \\
\hline Obi & $\begin{array}{l}\text { Robotic spoon that allows automatic or } \\
\text { semi-automatic feeding }\end{array}$ & Disabled & Level VII & NR \\
\hline $\begin{array}{l}\text { Mario } \\
\text { (National University } \\
\text { of Ireland) }\end{array}$ & Entertainment and reminders & $\begin{array}{l}\text { Older people \& } \\
\text { cognitively } \\
\text { impaired }\end{array}$ & Level VI & $\underline{58,59}$ \\
\hline $\begin{array}{l}\text { MiRo } \\
\text { (Consequential } \\
\text { Robotics) }\end{array}$ & $\begin{array}{l}\text { Autonomous robo-dog, reminds about } \\
\text { medications, hydration, temperature and } \\
\text { contacts emergency services }\end{array}$ & $\begin{array}{l}\text { Cognitively } \\
\text { impaired }\end{array}$ & Level VII & NR \\
\hline \multicolumn{5}{|l|}{ Therapeutic robots } \\
\hline $\begin{array}{l}\text { Giraff } \\
\text { (Camanio) }\end{array}$ & $\begin{array}{l}\text { Telepresence robot enables connection to } \\
\text { anyone world-wide, and monitors }\end{array}$ & $\begin{array}{l}\text { Older people \& } \\
\text { cognitively } \\
\text { impaired }\end{array}$ & Level III & 60 \\
\hline $\begin{array}{l}\text { Paro } \\
\text { (AIST) }\end{array}$ & $\begin{array}{l}\text { Therapeutic pet robot responds to } \\
\text { interaction }\end{array}$ & $\begin{array}{l}\text { Cognitively } \\
\text { impaired \& } \\
\text { children with } \\
\text { autism }\end{array}$ & Level I-II & $29-31,61$ \\
\hline \multicolumn{5}{|l|}{$\begin{array}{l}\text { Therapeutic } \\
\text { technology }\end{array}$} \\
\hline $\begin{array}{l}\text { Skype, FaceTime, } \\
\text { Google Hangouts } \\
\text { (various) }\end{array}$ & Communication apps for mobile devices & General use & Level IV & 62 \\
\hline $\begin{array}{l}\text { The Talking Photo } \\
\text { Album } \\
\text { (Communicate) }\end{array}$ & $\begin{array}{l}\text { Photos with individual messages for } \\
\text { reminiscence }\end{array}$ & $\begin{array}{l}\text { Cognitively } \\
\text { impaired }\end{array}$ & Level VII & NR \\
\hline $\begin{array}{l}\text { The Dawn Clock } \\
\text { (Dawn Clocks) }\end{array}$ & 5 medication and lifestyle alarms & $\begin{array}{l}\text { Cognitively } \\
\text { impaired }\end{array}$ & Level VII & NR \\
\hline $\begin{array}{l}\text { Automated } \\
\text { medication } \\
\text { dispensing service } \\
\text { (Philips) }\end{array}$ & Medication dispensing device & $\begin{array}{l}\text { Cognitively } \\
\text { impaired }\end{array}$ & Level VII & NR \\
\hline \multicolumn{5}{|l|}{ Apps } \\
\hline Luminosity & Brain training & MCI & Level VII & NR \\
\hline Alzheimer Master & $\begin{array}{l}\text { Plays voice recordings to remind } \\
\text { individuals to take medication, drink } \\
\text { water etc }\end{array}$ & $\begin{array}{l}\text { Cognitively } \\
\text { impaired }\end{array}$ & Level VII & NR \\
\hline $\begin{array}{l}\text { Bettercog } \\
\text { COMCOG }\end{array}$ & $\begin{array}{l}\text { Computerized cognitive training } \\
\text { programs }\end{array}$ & MCI & Level 1 & 63,64 \\
\hline
\end{tabular}


MCI, mild cognitive impairment; NR, not reported; RAMCIP, Robotic Assistant for MCI patients at Home. *Level I: systematic review or meta-analysis; Level II: randomized controlled trials; Level III: controlled trials without randomization; Level IV: case-control or cohort studies; Level V: systematic reviews of qualitative or descriptive studies; Level VI: qualitative or descriptive studies; Level VII: opinion or consensus. This hierarchical system is presented in Ref. ${ }^{65}$. 


\section{Glossary}

\section{Artificial intelligence}

An area of computer science that emphasizes the creation of machines that function and respond similarly to humans. Computerized artificial intelligence systems have been designed for speech recognition, machine learning, planning and problem solving.

\section{Internet of Things}

The interconnection of computing devices embedded in everyday objects, which enables them to send and receive data over the Internet.

\section{Social Baggage}

Metaphorically represents our experiences and memories that we bring with us from our past. 